\title{
Briefing: Super tall timber - Oakwood Tower
}

Robert M. Foster MEng, PhD

Research Associate, Department of Architecture, University of Cambridge, Cambridge, UK (corresponding author: rfm41@cam.ac.uk)
Michael H. Ramage MArch, PhD, CEng, MIStructE

Senior Lecturer in Architectural Engineering, Director Centre for Natural Material Innovation, Department of Architecture, University of Cambridge, Cambridge, UK

This briefing presents some of the early findings of the super tall timber project, an innovative research and design project exploring the potential of engineered timber as a structural material in the construction of tall buildings. The project brings researchers together with practising engineers and architects in a process that combines design-led research with research-led design in a constructive feedback loop, providing a new model for addressing the fundamental challenges of designing with a new structural material. The first result of this project is a concept design for a $300 \mathrm{~m}$ tall timber building sited in London.

\section{Introduction}

While not exactly a new material, engineered timber is not widely used as a construction material for the design of tall buildings. At present, the tallest modern building using timber as a primary structural material is the 14-storey Treet building in Bergen, Norway. While it is expected that timber will become increasingly common as a structural material for the construction of taller buildings, there is uncertainty as to how the material may be best used (Foster et al., 2016).

The first of a number of results from the super tall timber project is a concept design developed with Smith and Wallwork engineers and PLP Architecture, sited provocatively in London's Barbican complex. The design was presented to the then Mayor of London as an exemplar of the potential of engineered timber as a construction material and was promptly dubbed 'the toothpick' by the popular press. The building will be referred to here as Oakwood Tower (Figure 1) and will be used in this briefing to highlight some of the challenges and opportunities presented by engineered timber as a construction material.

\section{Self-weight}

Oakwood Tower is designed to be over $300 \mathrm{~m}$ tall; this means that it meets the definition of super tall as set out by the Council on Tall Buildings and Urban Habitats (CTBUH, 2016). Tall and super tall building design is characterised by the increasing influence of lateral and often dynamic loads on the structural design. Efficient design of such structures thus requires the designer to direct the permanent vertical loads into the lateral load resisting structure. This is expected to be particularly important for the design of super tall timber buildings due to the lightness of typical timber construction. Concrete-framed buildings have a typical bulk density of $\sim 300 \mathrm{~kg} / \mathrm{m}^{3}$ (Yang et al., 2004). Steel buildings, including the concrete decking that often makes up the greater part of their mass, have a typical bulk density of $160 \mathrm{~kg} / \mathrm{m}^{3}$ (Huang et al., 2007). The Treet building has an estimated bulk density of $\sim 140 \mathrm{~kg} / \mathrm{m}^{3}$, including $\sim 30 \mathrm{~kg} / \mathrm{m}^{3}$ of non-structural concrete ballast. This indicates that a timber structure without additional concrete, or a steel structure with a timber floor system, may have considerably less permanent vertical load to resist overturning and load reversal than conventional tall buildings. While the design approach adopted for this project did not prohibit the use of concrete, the designers preferred to avoid this initially so as not to side-step what was seen as a fundamental challenge presented by the use of engineered timber as a construction material. The intention to avoid supplementary mass also follows from the fact that the low self-weight of timber buildings is likely to provide an important part of their value proposition with regard to reduced foundation costs or even the reuse of existing foundations. As a result, the Oakwood Tower design incorporates no concrete in the superstructure and has a bulk density of $\sim 125 \mathrm{~kg} / \mathrm{m}^{3}$.

The importance of directing loads to the lateral load resisting system is compounded in a timber structural system due to the reduction in stiffness in typical timber connections when subjected to load reversal (Reynolds et al., 2014). This provides a strong incentive to minimise interior vertical load paths by maximising clear spans and directing vertical load into a lateral load resisting system at the perimeter. This has the architectural benefit of encouraging a 'soft' core that need not be central or even internal, allowing flexibility in space planning and the consideration of innovative vertical transportation 


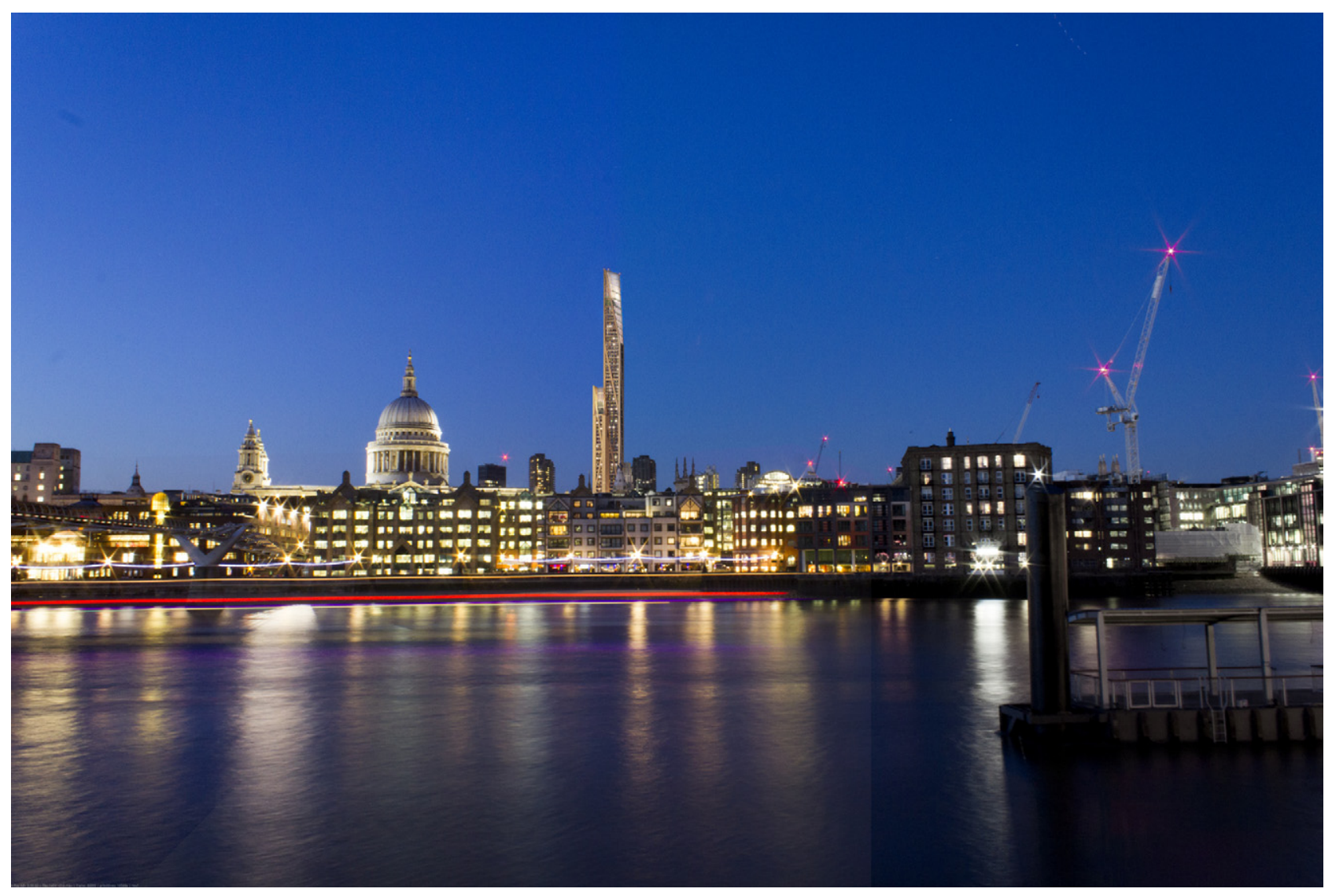

Figure 1. Architect's visualisation of Oakwood Tower. Reproduced with permission, ( ) PLP Architecture

solutions. A further architectural desire to lighten the presence of the tower, while achieving a variable wind profile to resist dynamic excitation, generated the spiral stepping of building height that also allows for buttressing of the central tower by the bundled sub-towers (Figure 2). Although this initially appears to lead to inefficient cladding (i.e. poor floor-plate perimeter to area ratio), this is offset by the improved natural light penetration and the markedly increased provision of high-value dual-aspect office or residential spaces.

\section{Mechanical properties}

Engineered timbers such as glued-laminated timber (glulam), cross-laminated timber (CLT) and laminated veneer lumber (LVL) obtain enhanced characteristic values of strength and stiffness compared with raw constituent timber material by virtue of homogenisation. Homogenisation refers to the reduction in variability associated with the lamination of $n>1$ constituent elements such as sawn boards or veneers in a sub-parallel load-sharing arrangement. Layers can also be laid-up cross-wise, as is the case in CLT, providing for enhanced dimensional stability and reduced anisotropy. The thickness of the CLT element allows out-of-plane loads to be resisted and reduces the propensity for buckling that has limited the application of other dimensionally stable panelised wood products such as plywood or oriented strand board (Brandner et al., 2015). Figure 3 shows the specific mean stiffness, as might reflect the stiffness for serviceability design, plotted against the specific design compressive strength, as might reflect ultimate strength design, for a selection of construction materials. Softwood timbers in particular exhibit specific compressive strength and stiffness comparable to those of steel, and significantly higher than of concrete, in the parallel-to-grain direction. The beneficial effect of homogenisation means that the strengths of engineered timbers such as glulam and LVL compare even more favourably. However, like un-homogenised timber, glulam and LVL as typically laid-up are highly anisotropic and their perpendicular-to-grain strength and stiffness are very much less than those parallel-to-grain. There is thus a trade-off to be considered in design between efficient use of 


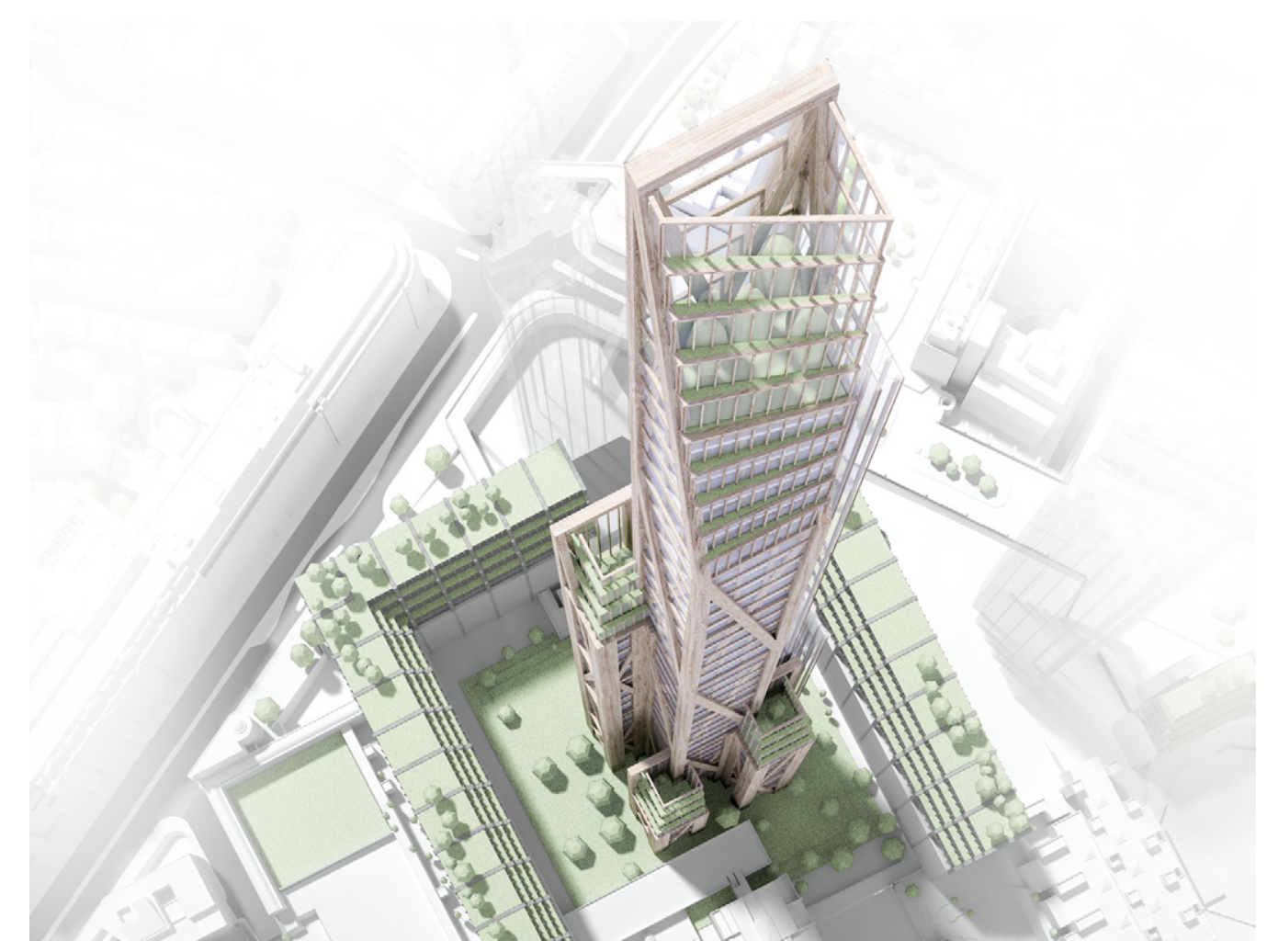

Figure 2. Architect's birds-eye visualisation of Oakwood Tower.

Reproduced with permission, (C PLP Architecture

parallel-to-grain capacity and mitigation of anisotropy through off-parallel use of material. This is a trade-off familiar to designers of fibre-reinforced composites and the transfer of understanding from fibre composite design is likely to be an important feature of future advanced engineered timber design.

Notwithstanding the potential for cross-lamination to mitigate some anisotropy, linear rather than planar elements were determined to be most efficient for withstanding the very high forces associated with the design of a super tall building. This drove the design towards a perimeter mega-truss system using homogeneous glulam or LVL timber elements with steel connections. Malo et al. (2016) suggest that such systems may require a similar mass of structural material and exhibit similar dynamic behaviour to equivalent steel mega-truss systems. Initial in situ output-only analysis of the dynamic behaviour of the Treet building using the random decrement method suggested that this may be the case (Reynolds et al., 2016).

The use of steel in the connections envisaged for Oakwood Tower is a response to the anisotropy of the timber. There is a fundamental requirement at these junctions for a more isotropic material, such as steel, to transfer forces between non-concentric, non-parallel elements. A consideration that informed the design approach adopted here was the recognition that concrete buildings typically contain something of the order of $100 \mathrm{~kg}$ of steel reinforcement per cubic metre of structural concrete, meaning that Oakwood could be up to about $10 \%$ steel by mass, without using any more steel than an equivalent concrete building. In reality, tall timber buildings can be expected to use much less steel than this. An analysis of Skidmore Owings and Merrill's (SOM, 2013) design for an 'all timber' redesign of the Dewitt-Chestnut building in Chicago (IL, USA) suggests that a timber design would use only approximately one-fifth of the steel of the existing concrete design.

\section{4. $\quad$ Fire resistance}

Large solid-timber elements have a high degree of inherent fire resistance against structural failure provided by the propensity of the surface to form a protective charred layer. Charring occurs at a well-established rate of $\sim 0.7-0.8 \mathrm{~mm} / \mathrm{min}$ in solidtimber materials. While there is no question that further development of the structural fire design of Oakwood Tower is required, the current conceptual design does positively address a number of key considerations. The vertical and bracing 


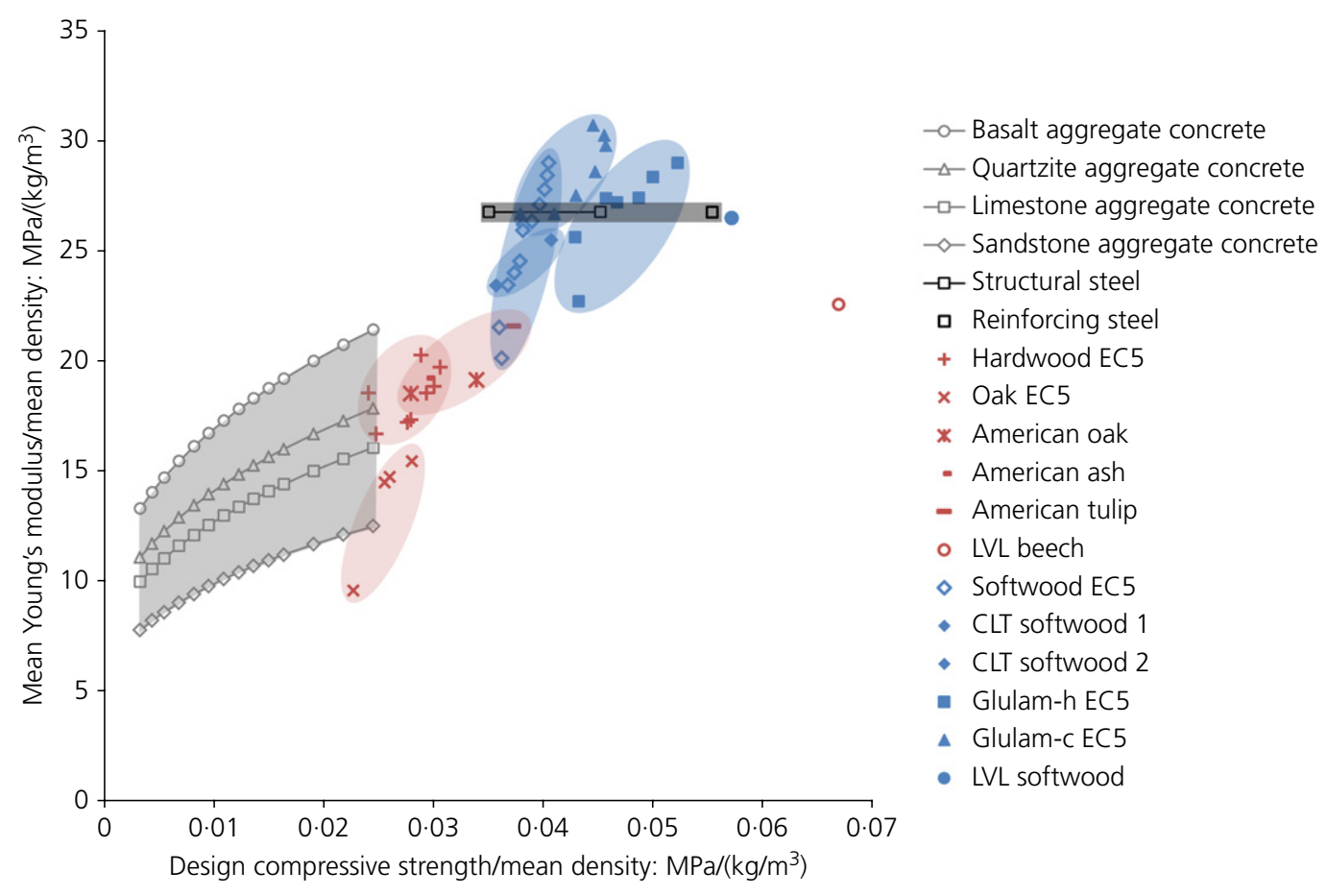

Figure 3. Specific stiffness and compressive strength of selected construction materials

elements that form the mega-truss and primary structural system are necessarily very large and are preliminarily sized for a combination of serviceability and ultimate considerations. In the accidental design case that corresponds to fire, the design loadings and material safety factors are substantially reduced. There is thus a considerable unused capacity in the structural section providing a very great thickness of potential sacrificial material for charring. Similarly, the widely spaced, large elements reduce the potential for rekindling.

\section{Robustness}

An area for further design review of the Oakwood Tower concept is in relation to robustness against disproportionate collapse. The current design may not permit sufficient redistribution of load by way of alternative load paths in the event of a corner column removal to permit a demonstration of safety through redundancy. These elements would therefore require further special design to demonstrate that they are sufficiently resistant to accidental actions, in order to justify their use as a key load path in a building of this size. The consideration of alternative load paths is likely to pose a challenge for buildings using structural timber due to the anisotropy of the elements and the resulting dependence of connection strength on the direction of loading. However, the relative lightness of buildings constructed using timber does mean that the loads to be redirected are considerably smaller than those for a conventional building. The relatively high material safety factors applicable to timber also prove beneficial when reduced in an accidental design situation.

\section{Conclusions}

The use of timber as a construction material at the scale considered for Oakwood Tower has raised a number of areas requiring further investigation in relation to the performance of the engineered material and its use in structural systems. At the materials level, these include the effects of size, hygrothermal variations, time dependency and weathering on material performance. At the systems level, they include methods for creating tight-fit or preloaded connections in order to increase the stiffness of joints under unidirectional load and under load reversal, the potential of 'mega-carpentry' for the formation of principally compressive element-to-element connections, and design for fire and robustness. The favourable specific strength and stiffness of engineered timber combined with its low density allows potential for very efficient long-span floor solutions. However, strategies for mitigating the resulting dynamic effects, such as economical tuned mass damper systems, require further development. A further consideration that has recurred in various forms during this preliminary phase of research has been the relationship between material variability and the 
structural system within which that material is used. Eurocode 5 (BSI, 2004) does allow limited consideration of redundancy and redistributive capacity of a structural arrangement through a ' $k$ ' factor. However, there may be potential to develop more precise relationships between the sensitivity of a system to the performance of individual elements and the required variability of the properties of the materials constituting those elements.

\section{Future direction}

Oakwood Tower and the other concept designs developed as part of the super tall timber project represent only the first phase of the research. The second phase will involve a series of experimental investigations into the actual performance of engineered timber as a construction material used at the scale considered in these designs. The experimental results will then be fed back into the design process so that the design can be further developed and improved. The authors' expectation is that this combination of research-led design with design-led research will lead to a rapid development of understanding of the use of engineered timber as a construction material.

\section{Acknowledgements}

The authors thank their collaborators in the design of Oakwood Tower: Simon Smith of Smith and Wallwork engineers, and Ron Bakker and Kevin Flanagan of PLP Architecture, for their generous contribution of time and creativity. The authors also gratefully acknowledge the financial support of the Engineering and Physical Sciences Research Council under grant EP/M01679X/1. Data supporting this paper can be obtained at the University of Cambridge's institutional repository (http://dx.doi.org/10.17863/CAM.515).

\section{REFERENCES}

Brandner R, Flatscher G, Ringhofer A, Schickhofer G and Thiel A (2015) Cross laminated timber (CLT): overview and development. European Journal of Wood Products 74(3): 331-351.

BSI (2004) EN 1995-1-1: Eurocode 5: Design of timber structures - part 1-1: general - common rules and rules for buildings. BSI, London, UK.

CTBUH (Council on Tall Buildings and Urban Habitats) (2016) Criteria for the Defining and Measuring of Tall Buildings. CTBUH, Chicago, IL, USA. See http://www.ctbuh. org/LinkClick.aspx?fileticket $=$ zvoB1S4nMug $\% 3 \mathrm{~d} \&$ tabid= 446\&language $=$ en-US (accessed 29/04/2016).

Foster RM, Reynolds TPS and Ramage MH (2016) Proposal for defining a tall, timber building. Journal of Structural Engineering, http://dx.doi.org/10.1061/(ASCE)ST.1943$541 X .0001615$

Huang S, Li QS and Xu S (2007) Numerical evaluation of wind effects on a tall steel building by CFD. Journal of Constructional Steel Research 63(5): 612-627.

Malo KA, Abrahamsen RB and Bjertnaes MA (2016) Some structural design issues of the 14-storey timber framed building 'Treet' in Norway. European Journal of Wood and Wood Products 74(3): 407-424.

Reynolds T, Harris R and Chang WS (2014) Stiffness of dowel-type timber connections under pre-yield oscillating loads. Engineering Structures 65(21): 21-29.

Reynolds TPS, Feldmann A, Harris R, Chang WS and Dietsch P (2016) Design parameters for lateral vibration of multi-storey timber buildings. In International Network of Timber Engineering Research, Graz, Austria (Rainer Gorlacher (ed.)). Timber Scientific Publishing, Karlesruhe, Germany.

SOM (Skidmore Owings and Merrill) (2013) Timber Tower Research Project: Final Report. SOM, Chicago, IL, USA. Yang J, Agrawal A, Samali B and Wu J (2004) Benchmark problem for response control of wind-excited tall buildings. ASCE Journal of Engineering Mechanics 130(4): 437-446.

\section{HOW CAN YOU CONTRIBUTE?}

To discuss this briefing, please email up to 500 words to the editor at journals@ice.org.uk. Your contribution will be forwarded to the author(s) for a reply and, if considered appropriate by the editorial board, it will be published as discussion in a future issue of the journal.

Proceedings journals rely entirely on contributions from the civil engineering profession (and allied disciplines). Information about how to submit your paper online is available at www.icevirtuallibrary.com/page/authors, where you will also find detailed author guidelines. 